\title{
Berberine induces apoptosis and arrests the cell cycle in multiple cancer cell lines
}

\author{
Qian $\mathrm{Li}^{1}$, Hui $\mathrm{Zhao}^{2}$, Weimin Chen², Ping Huang ${ }^{2}$
}

\author{
${ }^{1}$ Department of Radiology, Tongji Hospital, Tongji Medical College, Huazhong \\ University of Science and Technology, Wuhan, China \\ 2Department of Stomatology, Tongji Hospital, Tongji Medical College, Huazhong \\ University of Science and Technology, Wuhan, China
}

Submitted: 15 October 2020; Accepted: 1 February 2021

Online publication: 21 March 2021

Arch Med Sci

DOI: https://doi.org/10.5114/aoms/132969

Copyright $\odot 2021$ Termedia \& Banach

\section{Abstract}

Introduction: To examine the anti-cancer effects of berberine on multiple cancer cell lines, and to clarify the underlying molecular mechanisms.

Material and methods: The $\mathrm{IC}_{50}$ values for the action of berberine on Tca8113 (oral squamous cell carcinoma), CNE2 (nasopharyngeal carcinoma cell), MCF-7 (breast cancer), Hela (cervical carcinoma), and HT29 (colon cancer) cells were determined by MTT cell viability assay. Early apoptosis and cell cycle arrest were examined by flow cytometry with annexin $V$ and propidium iodide $(\mathrm{PI})$ staining, respectively. For expression of BAX and BCL-2 genes and proteins were detected by real-time PCR and western blotting, respectively.

Results: Berberine displayed a cytotoxic effect on all the cell lines tested. The $I C_{50}$ values were determined (Tca8113, $218.52 \pm 18.71$; CNE2, 249.18 \pm 18.14; MCF-7, $272.15 \pm 11.06$; Hela, $245.18 \pm 17.33$; and HT29, $52.37 \pm 3.45$ ). $\mathrm{PI}$ staining revealed that berberine treatment resulted in cell cycle arrest at $\mathrm{G} 2 / \mathrm{M}$. The treatment also induced early apoptosis as shown by annexin $\mathrm{V}$ staining. In addition, berberine significant elevated gene and protein expression of BAX, which was accompanied by substantial decreases in BCL-2 gene and protein levels. The effects of berberine on BAX and BCL-2 were time-dependent.

Conclusions: Berberine exhibited cytotoxic effects on multiple cancer cell lines by inducing apoptosis and cell cycle arrest. The BCL-2/BAX signaling pathway may be the common pathway underlying the anti-tumor effect of berberine. The findings support the notion that berberine is a dietary compound that can be further developed into a drug candidate for cancer treatment.

Key words: berberine, human epithelial cancer cells, MTT assay, apoptosis, BCL-2, BAX.

\section{Introduction}

Cancer causes millions of deaths worldwide, and more unfortunately, its incidence in many countries is increasing. Nowadays, surgery, chemotherapy, radiation therapy, and immunotherapy are the four commonly used treatment modalities. For many cancers, surgical interventions are potentially curative; however, many tumors are at an advanced stage that cannot be managed by surgical resection at the time of diagnosis in many clinical scenarios. Chemotherapy, which inhibits multiplication

\author{
Corresponding author: \\ Ping Huang \\ Department of Stomatology, \\ Tongji Hospital, \\ Tongji Medical College \\ Huazhong University \\ of Science and Technology \\ No. 1095 Jiefang Road, \\ Wuhan, Hubei, \\ 430030, China \\ Phone: +86-15807192632 \\ E-mail: huangping_hust@ \\ hotmail.com
}


of cancer cells, is the major treatment option for most patients. The efficacy of chemotherapy has been widely documented [1, 2]; however, serious adverse effects associated with the use of chemotherapeutic drugs have also been reported [3-5]. Patients treated with chemotherapeutic drugs can develop drug resistance. For example, a significant number of patients with estrogen receptor-positive breast cancer are found to acquire resistance to tamoxifen $[6,7]$. Treatment of patients with cancer by chemotherapy, radiotherapy, and surgery is also challenged by the post-treatment tumor recurrence. It therefore remains imperative to identify new modalities for cancer treatment.

Naturally occurring compounds are rich resources for novel anti-cancer drug candidates. Medicinal herbs containing a bioactive alkaloid called berberine have long been used by medical practitioners in China, Unani, and India to treat malignant diseases [8]. The compound berberine has been shown to display potent anti-cancer effects in vitro and in vivo [9-12], of which the underlying mechanisms are largely attributed to induction of the cell cycle and apoptosis in cancer cells [13-15]. More importantly, berberine is relatively non-toxic to humans compared to chemotherapeutic drugs [16]. All these studies collectively suggest that berberine is a promising drug candidate warranting further indepth investigations. In the present study, we examined the cytotoxic effects of berberine on a panel of cancer cell lines including oral squamous cell carcinoma, nasopharyngeal carcinoma, breast cancer, cervical carcinoma, and colon cancer. We also deciphered the possible mechanism underlying the cytotoxicity of berberine towards cancer cells.

\section{Material and methods}

\section{Cell cultures and reagents}

Human oral squamous cell carcinoma Tca8113 cells were obtained from the Key Laboratory for Oral Biomedicine of Ministry of Education, Department of Endodontics, School and Hospital of Stomatology, Wuhan University, China. Human nasopharyngeal carcinoma CNE2 cells, human breast cancer MCF-7 cells, human cervical carcinoma Hela cells, and human colon cancer HT29 cells were purchased from the China Center for Type Culture Collection (CCTCC), Wuhan, China. Tca8113 and HT29 cells were cultured in Dulbecco's Modified Eagle Medium (DMEM; Thermo Fisher Scientific Inc., MA, US). Hela and MCF-7 cells were maintained in RPMI-1640 (Thermo Fisher Scientific Inc.), while CNE2 cells were maintained in Minimum Essential Medium with Earle's Balanced Salts (MEM/EBSS; Thermo Fisher Scientific Inc.). All the culture media were supplemented with $5 \%$ fetal bovine serum and $1 \%$ streptomycin/ penicillin. For the culture of MCF-7 cells, human insulin-like growth factor $(1 \mu \mathrm{g} / \mathrm{ml})$ was also added. All the cell cultures were maintained in a $5 \%$ $\mathrm{CO}_{2}$ environment at $37^{\circ} \mathrm{C}$.

Berberine hydrochloride and dimethyl sulfoxide (DMSO) were obtained from Sigma-Aldrich Co. LLC (St. Louis, MO, USA). The stock solution of berberine was prepared by dissolving berberine hydrochloride in sterile water and filter-sterilized. 3-(4,5)-dimethylthiahiazo (-z-y1)-3,5-di-phenytetrazoliumromide (MTT) was purchased from Solarbio Science \& Technology Co., Ltd. (Beijing, China).

\section{MTT cell viability assay}

The effect of berberine on the viability of various cancer cell lines was examined using MTT assay. Cancer cells were seeded into 96 -well plates at a density of $1 \times 10^{6}$ cells/well, and on the next day, were treated with berberine of serial concentration (i.e. 12000, 6000, 3000, 1500, 750, 375, $188,94$, and $47 \mu \mathrm{M})$. Incubation was allowed for 48 hours. After the incubation, $50 \mu$ of MTT $(2 \mathrm{mg} / \mathrm{ml})$ was added. After three hours, the optical density at a wavelength of $600 \mathrm{~nm}$ was detected. The $I C_{50}$ value of each cancer cell was determined from three independent determinations.

\section{Annexin V staining for apoptosis}

Apoptosis of cancer cells after treatment with berberine was studied using annexin $\mathrm{V}$ staining (KeyGen Biotech, Nanjing, China). In brief, cancer cells were treated with berberine hydrochloride of concentration equivalent to the respective $I C_{50}$ for different time points $(0,6,12,24$, and 36 hours). The treated cells were then stained with annexin V-FITC and propidium iodide (PI, $10 \mu \mathrm{g} / \mathrm{ml}$ ). The proportion of apoptotic cells (annexin V-positive/ PI-negative) was determined using flow cytometry by FACSCalibur (Becton Dickinson, Franklin Lakes, NJ, USA).

\section{Cell cycle analysis}

The effect of berberine on the cell cycle of cancer cells was examined by PI staining. Briefly, cancer cells were treated with berberine hydrochloride of concentration equivalent to the respective $\mathrm{IC}_{50}$ for different time points $(0,6,12,24$, and 36 hours). Cancer cells were fixed with ethanol for overnight, treated with RNase A $(1 \mathrm{mg} / \mathrm{ml})$, and finally stained with PI $(100 \mu \mathrm{g} / \mathrm{ml})$. PI-stained cells were quantified using flow cytometry by FACSCalibur (Becton Dickinson), with the cell cycle being analyzed by CellQuest and Modfit software.

\section{Quantitative real-time PCR}

The expression of BAX and BCL-2 genes after berberine treatment was examined using quantita- 
tive real-time PCR. Cancer cell lines were subjected to berberine hydrochloride treatment of a concentration equivalent to the respective $I C_{50}$ for different time points $(0,6,12,24$, and 36 hours). After treatment, total RNA was isolated from the treated cells using TRIZOL (Thermo Fisher Scientific Inc.). First-strand cDNA was then synthesized from the isolated RNA using Superscript II reverse transcriptase (Thermo Fisher Scientific Inc.). Amplification of $B A X$ and $B C L-2$ was performed using TOYOBO THUNDERBIRD SYBR qPCR Mix (Osaka, Japan) by the $A B I 7500$ Real-time System (Thermo Fisher Scientific Inc.) with the following oligonucleotides: H-BCL-2, 5'-CATTGGGAAGTTTCAAATCAGC-3' (sense) and 5'-CTTTGCATTCTTGGACGAGG-3' (antisense); H-BAX, 5'-TTGCTTCAGGGTTTCATCCA-3' (sense) and 5'-CAGCCTTGAGCACCAGTTTG-3' (antisense). Human actin (sense, 5'- GTCCACCGCAAATGCTTCTA-3'; antisense, 5'- TGCTGTCACCTTCACCGTTC -3') was also amplified as the internal control. Gene expression of both targets was determined as the expression relative to the control using the comparative cycle threshold method.

\section{Western blotting}

The expression of BAX and $\mathrm{BCL}-2$ proteins after berberine treatment was studied by western blotting. Whole cell lysate $(40 \mathrm{mg}$ ) from cancer cell lines, which were treated with berberine hydrochloride of concentration equivalent to the respective $\mathrm{IC}_{50}$ for different time points $(0,6,12$, 24 , and 36 hours), was resolved on $10 \%$ SDS-polyacrylamide gels and electroblotted on polyvinylidene fluoride membranes (Roche Applied Science, Germany). The blots were blocked overnight with $5 \%$ nonfat dry milk and probed with primary antibodies at dilutions recommended by the suppliers. Immunoblots were detected by horseradish peroxidase-conjugated secondary antibody (Pierce) using a chemiluminescence kit (Pierce) and photographed.

\section{Statistical analysis}

Data were analyzed using statistical software SPSS, and were presented as mean \pm standard derivation from at least three independent experiments.

\section{Results}

\section{Berberine suppressed cancer cell viability}

The suppression of cancer cell viability by berberine was studied using MTT viability assay after the cancer cells were incubated with berberine for 48 hours. Berberine displayed an in vitro cytotoxic effect on all the tested cell lines. The $\mathrm{IC}_{50}$ of berberine treatment for each cell line was deter- mined and compared (Table I). Colon cancer cell line HT29 was the most sensitive one among the five cell lines tested, with its $I C_{50}$ measuring 52.37 $\pm 3.45 \mu \mathrm{M}$. The $I C_{50}$ values of the remaining four cell lines were comparable to each other.

\section{Berberine induced G2/M-phase arrest}

Since the treatment of berberine resulted in suppression in cancer cell viability, we examined whether berberine would affect the cell cycle of different cancer cells by PI staining (Figure $1 \mathrm{~A}$ ). The proportion of cell cycle phases was determined, and results showed that berberine could induce cell arrest at the G2/M phase (Figure $1 \mathrm{~B}$ ). For Tca8113 and MCF-7, the maximal arrests were seen after berberine treatment for 12 hours. For Hela, CNE2, and HT29, the maxima arrest was observed at 24, 36, and 24 hours, respectively.

\section{Berberine triggered early apoptosis}

We also performed annexin $\mathrm{V}$ staining to examine the induction of apoptosis in cancer cells by berberine treatment (Figure $2 \mathrm{~A}$ ). The annexin $\mathrm{V}$-positive cells were quantified and the results demonstrated that apoptosis was increased by berberine treatment in all the cell lines tested in a time-dependent manner (Figure 2 B). To delineate the molecular mechanism by which berberine induced apoptosis in cancer cells, we used western blotting to examine the protein expression of apoptotic regulators $B A X$ and $B C L-2$ in berberine-treated cancer cell lines (Figure $3 \mathrm{~A}$ ). It was clearly demonstrated that berberine treatment could increase BAX protein expression; the elevation was accompanied with significant suppression of $B C L-2$. The effect of berberine on the protein expression of $B A X$ and $B C L-2$ was time-dependent. To investigate whether berberine would also regulate $\mathrm{BAX}$ and $\mathrm{BCL}-2$ at the transcriptional level, real-time PCR was employed to determine the gene expression of $\mathrm{BAX}$ and $\mathrm{BCL}-2$ after treatment of different cancer cells with berberine (Figure $3 \mathrm{~B}$ ). For BAX, its gene expression was substantially elevated by berberine treatment in all cell lines tested except in HT29, while for BCL-2, its gene expression was significantly suppressed

Table I. The $I C_{50}$ values for the killing of different cancer cells by berberine as determined by MTT assay

\begin{tabular}{|lc|}
\hline Cell lines & IC $_{50}(\mu \mathrm{M})$ \\
\hline Tca8113 & $218.52 \pm 18.71$ \\
\hline CNE2 & $249.18 \pm 18.14$ \\
\hline MCF-7 & $272.15 \pm 11.06$ \\
\hline Hela & $245.18 \pm 17.33$ \\
\hline HT29 & $52.37 \pm 3.45$ \\
\hline
\end{tabular}




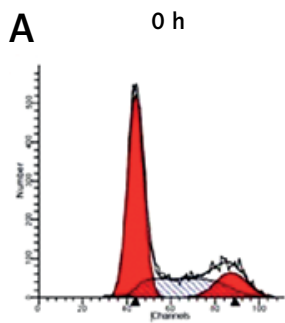

$6 \mathrm{~h}$

$12 \mathrm{~h}$

$36 \mathrm{~h}$
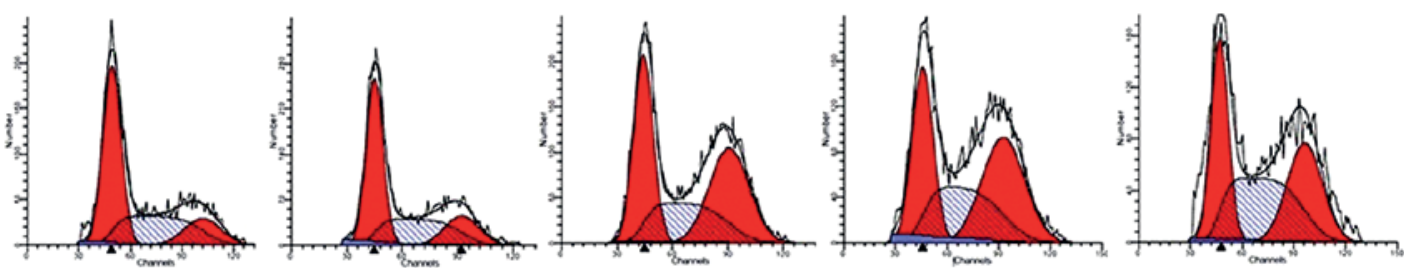

Hela
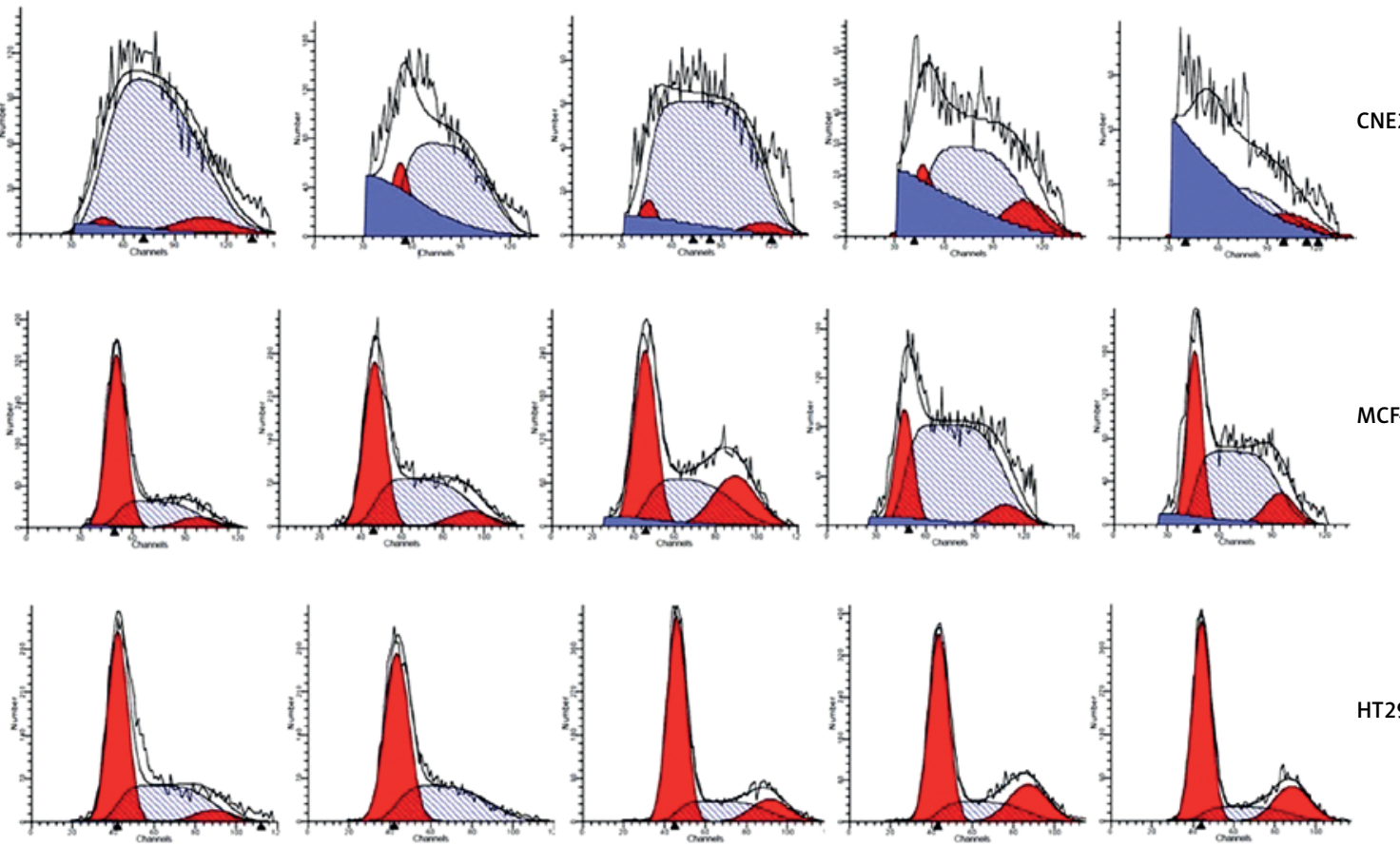

B

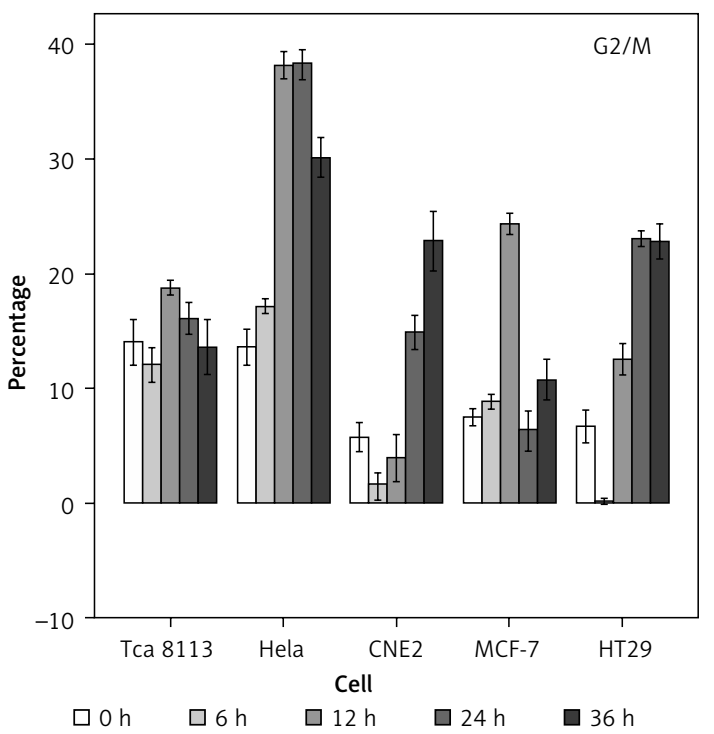

Figure 1. Berberine arrested cancer cell cycle progression at G2/M phase. A - The cell cycles of cancer cells were analyzed by flow cytometry, with the nuclear DNA of berberine-treated cells labeled with $\mathrm{PI}$. A representative set of histograms from three independent experiments is shown. B - The proportions of G2/M phase of different cancer cells were quantified and compared. Data are presented as the mean \pm SD of three independent experiments 
A
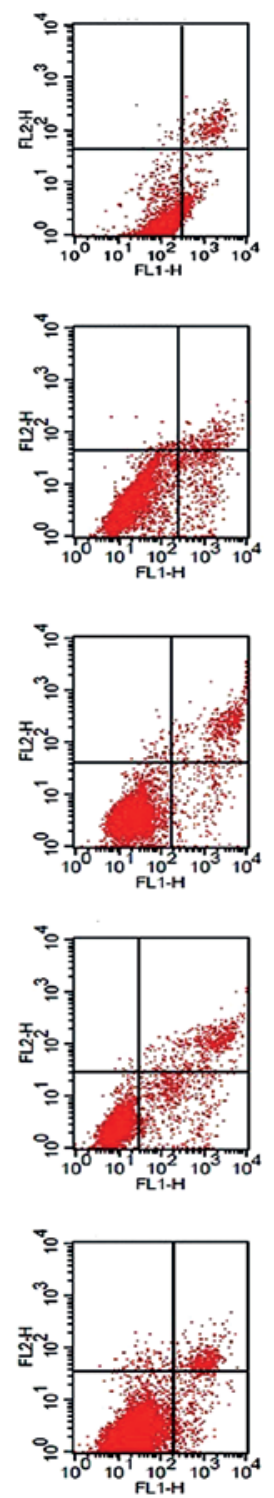

$6 \mathrm{~h}$
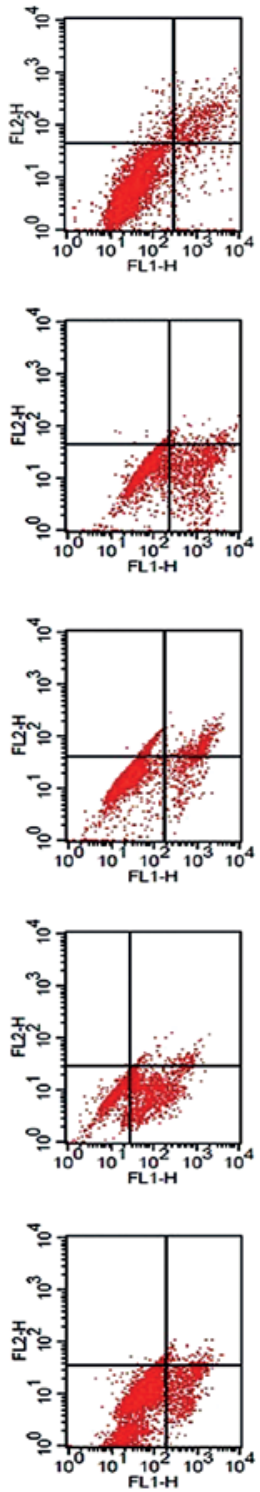

$12 \mathrm{~h}$
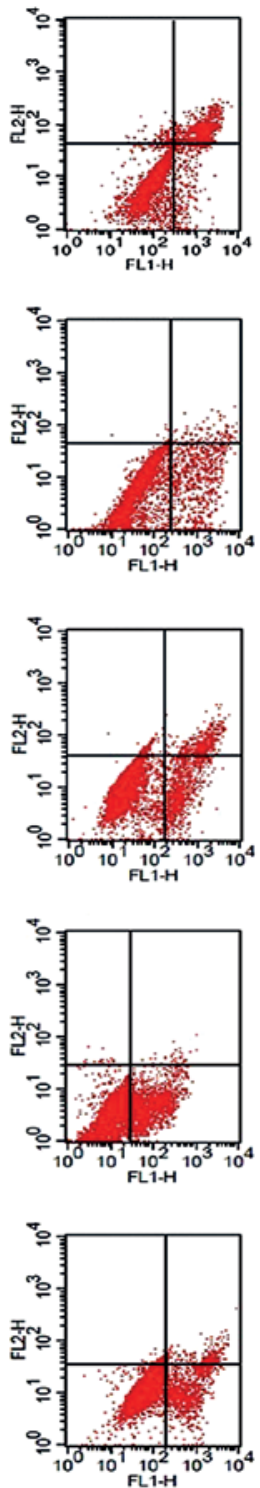

$24 \mathrm{~h}$
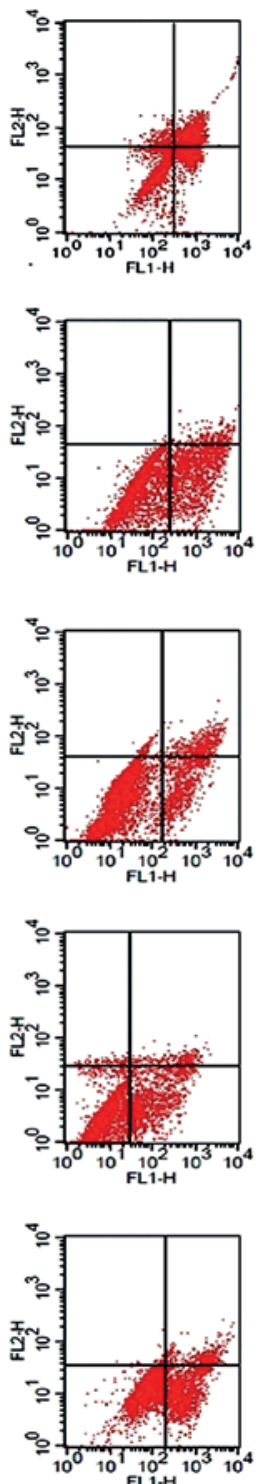

$36 \mathrm{~h}$
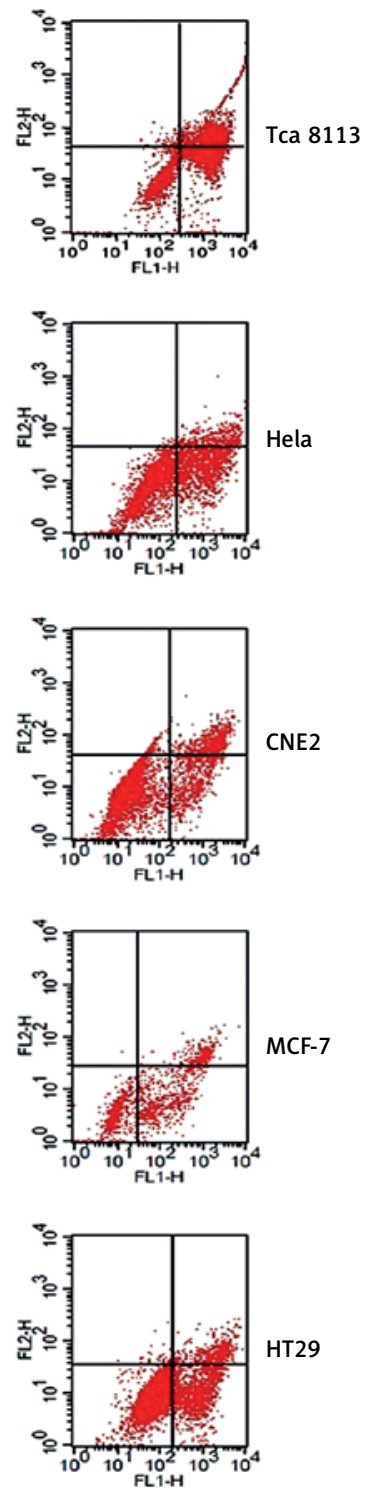

B

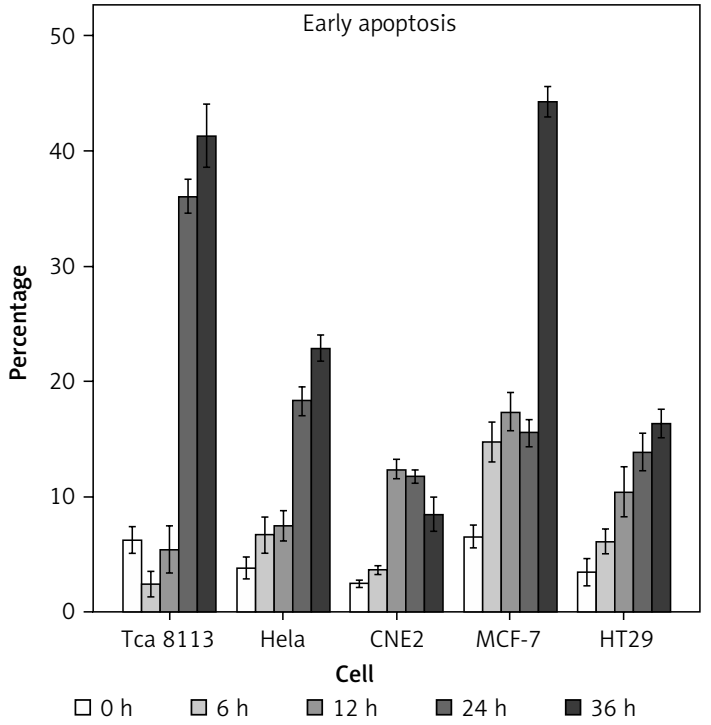

Figure 2. Berberine induced apoptosis in multiple cancer cells. A - Plots of sorted apoptotic cells. Early apoptotic cells (annexin V+ and PI-) are displayed in the lower right quadrant and late apoptotic cells (annexin $\mathrm{V}+$ and $\mathrm{Pl}+$ ) are shown in the upper right quadrant. A representative set of sorted apoptotic cell plots from three independent experiments is shown. B - The early apoptotic cells were counted by flow cytometry. Data are presented as the mean \pm SD of three independent experiments 
A

$0 \mathrm{~h} \quad 6 \mathrm{~h} \quad 12 \mathrm{~h} \quad 24 \mathrm{~h} \quad 36 \mathrm{~h}$
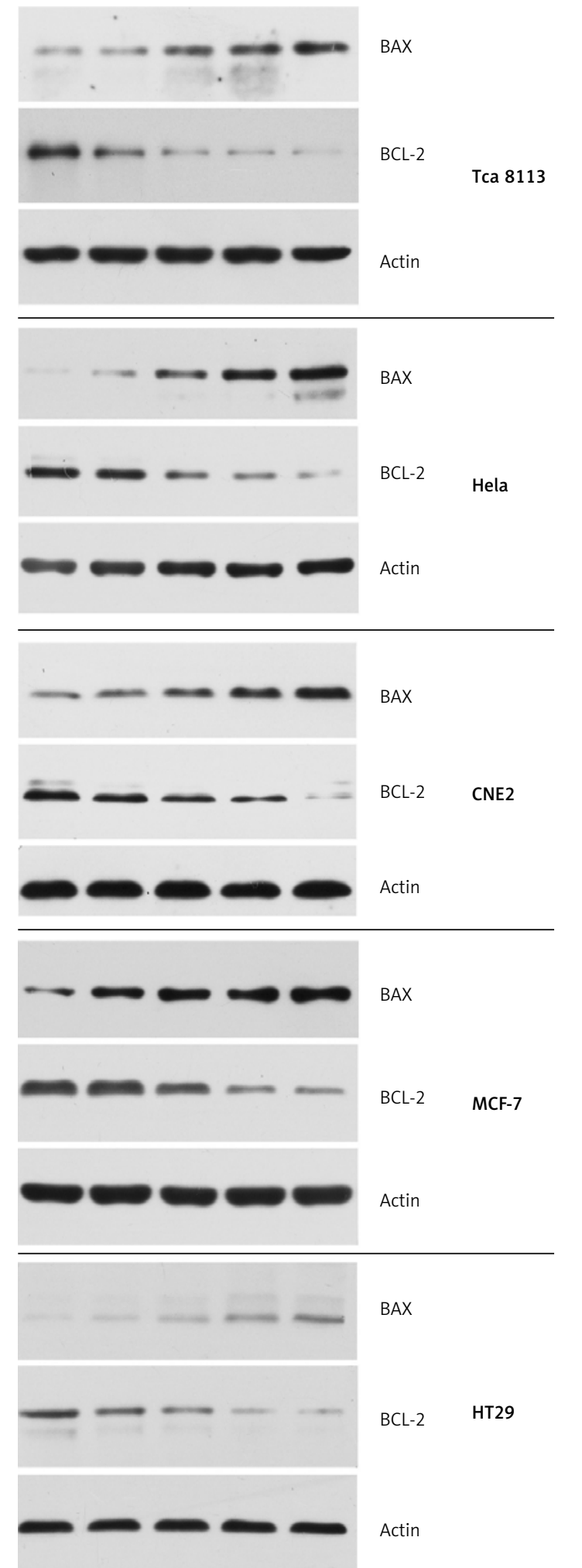

B

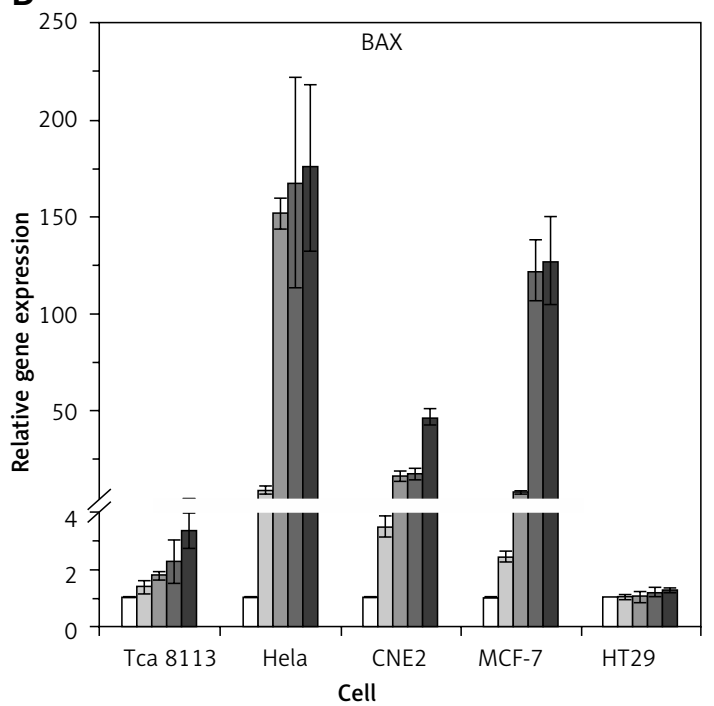

$\square 0 \mathrm{~h} \quad \square 6 \mathrm{~h} \quad \square 12 \mathrm{~h} \quad \square 24 \mathrm{~h} \quad \square 36 \mathrm{~h}$

C

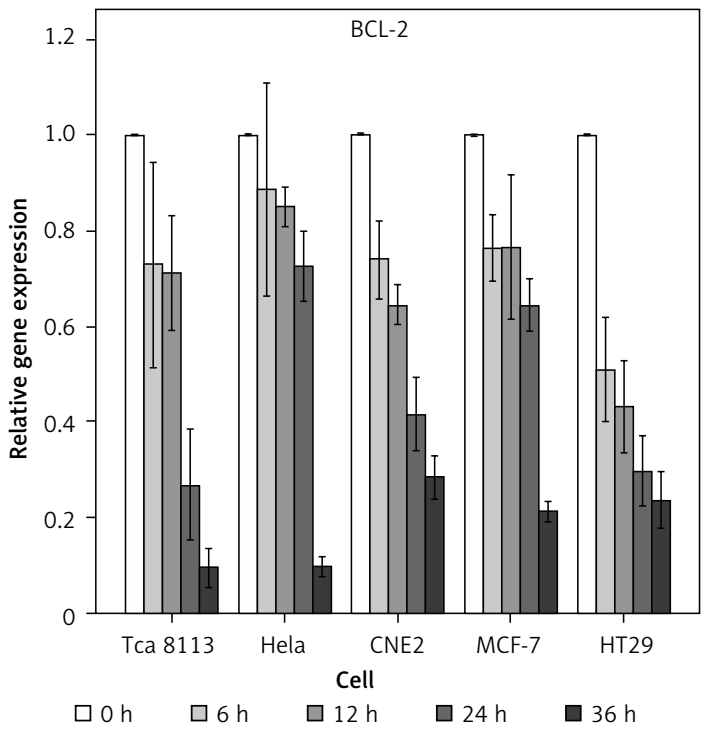

Figure 3. Berberine modulated the expression of BAX and BCL-2 in multiple cancer cells. A - Five cancer cells were exposed to berberine hydrochloride (respective $I C_{50}$ for each cell line) for $0,6,12,24$ and $36 \mathrm{~h}$. The protein levels of $\mathrm{BAX}$ and BCL-2 were determined by Western blotting assays. The representative set of western blotting from three independent experiments is shown. $\mathbf{B}$ - Relative mRNA expression of BAX at indicated time points. $\mathbf{C}-$ Relative mRNA expression of BCL-2 at indicated time points. Data are presented as the mean \pm SD of three independent experiments 
in all cell lines tested. Again, the effect of berberine on the gene expression of BAX and BCL-2 was time-dependent.

\section{Discussion}

The present study demonstrated the anti-cancer property of berberine on multiple cancer cell lines including oral squamous cell carcinoma, nasopharyngeal carcinoma, breast cancer, cervical carcinoma, and colon cancer. Our in-depth mechanistic studies suggested that the anti-cancer property of berberine was apparently attributed to its ability to trigger apoptosis and to induce cell cycle arrest at G2/M phase. Treatment of cancer remains challenging, despite the recent advents in targeted therapy and immunotherapy. New therapeutic agents for cancer treatment are urgently needed. Over the last decades, in the search of new therapeutic agents, many naturally occurring dietary compounds have been shown to display profound anti-cancer properties with minimal toxicity in various in vitro and animal models [17-19].

Berberine, which is an alkaloid that exists as the major bioactive compound in many medicinal herbs, is one of the naturally occurring compounds that attract intense investigations. The anti-cancer effects of berberine have been characterized, suggesting that the compound could inhibit DNA and protein synthesis and arrested cell cycle progression [20-24]. In line with these studies, we further demonstrated the anti-cancer effect of berberine on different cancer cell lines including Tca8113, Hela, CNE2, MCF-7 and HT29 cells. In these cell lines, berberine prevented cell cycle progression at $\mathrm{G} 2 / \mathrm{M}$ phase. The arrest of the cell cycle at G2/M by berberine was also reported in BALB/3T3 cells $[25,26]$, while in murine $L 1210$ cells, berberine arrested the cell cycle at G0/G1 phase [27]. Our data together with the published findings collectively suggest that the regulation of the cell cycle by berberine would be cell type-dependent.

Induction of apoptosis represents one of the key mechanisms of action of chemotherapy, radiotherapy and immunotherapy [28-30]. Apoptosis is a tightly regulated process involving many anti- and pro-apoptotic proteins. Overexpression of anti-apoptotic members of the $\mathrm{Bcl}-2$ family has been implicated in the chemoresistance of cancers [31-33], whereas high levels of pro-apoptotic proteins, e.g. BAX, promote apoptosis and sensitize tumor cells to various anticancer therapies $[19,20,34]$. In this context, whether cancer cells would be committed to apoptosis partly depends upon the balance between anti- and pro-apoptotic proteins. Our present study clearly showed that berberine treatment could induce apoptosis in multiple cancer cell lines by increasing BAX and decreasing $\mathrm{BCL}-2$ expression. The consistent changes in expression of BAX and BCL-2 indicated that the $B A X / B C L-2$ signaling pathway may represent a common mechanism of berberine to inhibit the growth of tumors, which is a promising direction for developing strategies in the treatment of various tumors. The increased $\mathrm{BAX}$ might override the protective action of $\mathrm{BCL}-2$ on cancer cells; however, the elevation of BAX alone was found not sufficient to initiate apoptosis in the absence of additional stimuli [25]. The berberine-induced apoptosis likely involved other pro-apoptotic pathways or factors yet to be identified.

To summarize, our results clearly illustrated the anti-cancer action of berberine on multiple cancer cell lines, covering oral squamous cell carcinoma, nasopharyngeal carcinoma, breast cancer, cervical carcinoma, and colon cancer. Advanced tumors of these cancers are difficult to treat, despite the recent advents in new treatment modalities such as immunotherapy. Berberine holds promise as a drug candidate that can be developed into new cancer drugs with minimal toxicity. Our study and findings from other research groups worldwide collectively suggest that berberine can trigger apoptosis and induce cell cycle arrest in cancer cells. Nevertheless, the pharmacologic actions of berberine will require further in-depth investigation in different animal models of cancers.

\section{Acknowledgments}

This study was supported by grants from the National Natural Science Foundation of China (Youth Foundation; No. 81602742, belonging to Ping Huang). The authors thank the colleagues who have contributed to this study.

\section{Conflict of interest}

The authors declare no conflict of interest.

\section{References}

1. Mahtani RL, Stein A, Vogel CL. High-dose estrogen as salvage hormonal therapy for highly refractory metastatic breast cancer: a retrospective chart review. Clin Ther 2009; 31 Pt 2: 2371-8.

2. Damon LE, Cadman EC. The metabolic basis for combination chemotherapy. Pharmacol Ther 1988; 38: 73-127.

3. Ketiku KK, Ajekigbe AT. Chemotherapy of breast cancer in Nigerians: side-effects and quality of life. Clin Oncol 1990; 2: 153-5.

4. Coates A, Abraham S, Kaye SB, et al. On the receiving end-patient perception of the side - effects of cancer chemotherapy. Eur J Cancer Clin Oncol 1983; 19: 203-8.

5. Bae WK, Hwang JE, Shim HJ, et al. Multicenter phase II study of weekly docetaxel, cisplatin, and S-1 (TPS) induction chemotherapy for locally advanced squamous cell cancer of the head and neck. BMC Cancer 2013; 13: 102.

6. Early Breast Cancer Trialists' Collaborative Group. Tamoxifen for early breast cancer: an overview of the randomised trials. Lancet 1998; 351: 1451-67. 
7. Lazarus P, Sun D. Potential role of UGT pharmacogenetics in cancer treatment and prevention: focus on tamoxifen and aromatase inhibitors. Drug Metab Rev 2010; 42: 182-94.

8. Chaudhury RR. Plants with possible antifertility activity. Spec Rep Ser Indian Counc Med Res 1966; 55: 3-19.

9. Liu Z, Liu Q, Xu B, et al. Berberine induces p53-dependent cell cycle arrest and apoptosis of human osteosarcoma cells by inflicting DNA damage. Mutat Res 2009; 662: 75-83.

10. Katiyar SK, Meeran SM, Katiyar N, Akhtar S. p53 Cooperates berberine-induced growth inhibition and apoptosis of non-small cell human lung cancer cells in vitro and tumor xenograft growth in vivo. Mol Carcinog 2009; 48: 24-37.

11. Meeran SM, Katiyar S, Katiyar SK. Berberine-induced apoptosis in human prostate cancer cells is initiated by reactive oxygen species generation. Toxicol Appl Pharmacol 2008; 229: 33-43.

12. Hwang JM, Kuo HC, Tseng TH, Liu JY, Chu CY. Berberine induces apoptosis through a mitochondria/caspases pathway in human hepatoma cells. Arch Toxicol 2006; 80: 62-73.

13. Mahata S, Bharti AC, Shukla S, Tyagi A, Husain SA, Das BC. Berberine modulates AP-1 activity to suppress HPV transcription and downstream signaling to induce growth arrest and apoptosis in cervical cancer cells. Mol Cancer 2011; 10: 39.

14. Yang IW, Chou CC, Yung BY. Dose-dependent effects of berberine on cell cycle pause and apoptosis in Balb/c 3T3 cells. Naunyn Schmiedebergs Arch Pharmacol 1996; 354: 102-8.

15. Xu LN, Lu BN, Hu MM, et al. Mechanisms involved in the cytotoxic effects of berberine on human colon cancer HCT-8 cells. Biocell 2012; 36: 113-20.

16. Jantova S, Cipak L, Letasiova S. Berberine induces apoptosis through a mitochondrial/caspase pathway in human promonocytic U937 cells. Toxicol In Vitro 2007; 21: 25-31.

17. Pan $\mathrm{MH}, \mathrm{Ho} \mathrm{CT}$. Chemopreventive effects of natural dietary compounds on cancer development. Chem Soc Rev 2008; 37: 2558-74.

18. Galati G, O'Brien PJ. Potential toxicity of flavonoids and other dietary phenolics: significance for their chemopreventive and anticancer properties. Free Radic Biol Med 2004; 37: 287-303.

19. Ramos S. Cancer chemoprevention and chemotherapy: dietary polyphenols and signalling pathways. Mol Nutr Food Res 2008; 52: 507-26.

20. Kong B, Huang S, Wang W, et al. Arsenic trioxide induces apoptosis in cisplatin-sensitive and -resistant ovarian cancer cell lines. Int J Gynecol Cancer 2005; 15: 872-7.

21. Lin JP, Yang JS, Lee JH, Hsieh WT, Chung JG. Berberine induces cell cycle arrest and apoptosis in human gastric carcinoma SNU-5 cell line. World J Gastroenterol 2006; 12: 21-8.

22. Kuo CL, Chi CW, Liu TY. The anti-inflammatory potential of berberine in vitro and in vivo. Cancer Lett 2004; 203 127-37.

23. Creasey WA. Biochemical effects of berberine. Biochem Pharmacol 1979; 28: 1081-4.

24. Schmeller T, Latz-Bruning B, Wink M. Biochemical activities of berberine, palmatine and sanguinarine mediating chemical defence against microorganisms and herbivores. Phytochemistry 1997; 44: 257-66.
25. Hoshi A, Ikekawa T, Ikeda Y, Shirakawa S, ligo M. Antitumor activity of berberrubine derivatives. Gan 1976; 67: 321-5.

26. Dai X, Yamasaki K, Yang L, et al. Keratinocyte G2/M growth arrest by 1,25-dihydroxyvitamin D3 is caused by Cdc2 phosphorylation through Wee1 and Myt1 regulation. J Invest Dermatol 2004; 122: 1356-64.

27. Jantova S, Cipák L, Cernáková M, Kostálová D. Effect of berberine on proliferation, cell cycle and apoptosis in HeLa and L1210 cells. J Pharm Pharmacol 2003; 55: 1143-9.

28. Kaufmann SH, Earnshaw WC. Induction of apoptosis by cancer chemotherapy. Exp Cell Res 2000; 256: 42-9.

29. Chinnaiyan AM, Prasad U, Shankar S, et al. Combined effect of tumor necrosis factor-related apoptosis-inducing ligand and ionizing radiation in breast cancer therapy. Proc Natl Acad Sci USA 2000; 97: 1754-9.

30. Hersey P. Impediments to successful immunotherapy. Pharmacol Ther 1999; 81: 111-9.

31. Reed JC. Bcl-2 family proteins. Oncogene 1998; 17: 3225-36.

32. Evan G, Littlewood T. A matter of life and cell death. Science 1998; 281: 1317-22.

33. Villunger A, Egle A, Kos M, et al. Drug-induced apoptosis is associated with enhanced Fas (Apo-1/CD95) ligand expression but occurs independently of Fas (Apo-1/ CD95) signaling in human T-acute lymphatic leukemia cells. Cancer Res 1997; 57: 3331-4.

34. Kim DW, Ahan SH, Kim TY, et al. Enhancement of arsenic trioxide $(\mathrm{As}(2) \mathrm{O}(3))$ - mediated apoptosis using berberine in human neuroblastoma SH-SY5Y cells. J Korean Neurosurg Soc 2007; 42: 392-9. 